УДК 796

DOI https://doi.org/10.26661/2663-5925-2021-2-09

\title{
ФОРМУВАННЯ ВМІНЬ І ВДОСКОНАЛЕННЯ РУХОВИХ НАВИЧОК СТАРШОКЛАСНИКІВ НА УРОКАХ ФІЗИЧНОЇ КУЛЬТУРИ
}

\author{
Товстопятко Ф. Ф. \\ кандидат філософських наук, \\ доиент кафедри теорії та методики фізичної культури і спорту \\ Запорізький національний університет \\ вул. Жуковського, 66, Запоріжжя, Украӥна \\ orcid.org/0000-0002-4708-5916 \\ tovstopatkofedor@gmail.com \\ Тищенко В. О. \\ доктор наук з фізичного виховання і спорту, професор, \\ професор кафедри теорії та методики фізичної культури і спорту \\ Запорізький національний університет \\ вул. Жуковського, 66, Запоріжжя, Украӥна \\ orcid.org/0000-0002-9540-9612 \\ valeritysh@gmail.com \\ Соколова О. В. \\ кандидат наук з фізичного виховання і спорту, доцент, \\ доиент кафедри теорії та методики фізичної культури і спорту \\ Запорізький національний університет \\ вул. Жуковського, 66, Запоріжжя, Україна \\ orcid.org/0000-0003-1062-0935 \\ sokolova-znu@gmail.com \\ Стьопочкін Я. С. \\ студент магістратури факультету фізичного виховання, здоров'я і туризму \\ Запорізький начіональний університет \\ вул. Жуковського, 66, Запоріжжя, Україна \\ orcid.org/0000-0001-6201-4596 \\ handball.survey@gmail.com
}

Ключові слова: волейбол, варіативний модуль, фізична підготовленість, технічна підготовленість, юнаки.
Аналіз шкільних програм із фізичного виховання вказує на те, що в наш час немає реальної можливості здійснити важливий принцип системи фізичного виховання - забезпечити диференційований та індивідуальний підхід до учнів з урахуванням стану їхнього здоров’ я, фізичного розвитку і фізичної підготовленості. Саме тому в більшості випускників середньої школи рівень розвитку рухових здібностей не відповідає тим вимогам, які висуває суспільство до фізичної підготовленості молодого покоління. Мета дослідження - підвищити ефективність формування вмінь і вдосконалення рухових навичок старшокласників на уроках фізичної культури у варіативному модулі «Волейбол». Об'єкт дослідження урок фізичної культури у варіативному модулі «Волейбол». Предмет дослідження - показники фізичної та технічної підготовленості. Суб'єкт дослідження - хлопці старшого шкільного віку. Методи дослідження: аналіз і узагальнення літературних джерел за темою дослідження, педагогічні спостереження, тестування фізичної підготовленості, тестування технічної підготовленості, методи математичної статистики. 
Результати дослідження. Проаналізована науково-методична література за темою дослідження дозволила більш детально вивчити особливості фізичної і технічної підготовки у волейболі, особливості розвитку фізичних якостей. Була розроблена й апробована на практиці методика підвищення ефективності формування вмінь і вдосконалення рухових навичок старшокласників на уроках фізичної культури у варіативному модулі «Волейбол». Використання нових, більш ефективних педагогічних рекомендацій сприяло формуванню вмінь і вдосконаленню рухових навичок старшокласників у процесі занять волейболом на уроках фізичної культури. Висновки. Застосування експериментальної методики в умовах контролю показників загальної фізичної підготовленості, а також під час виконання технічних елементів волейболу дозволило підвищити рівень підготовки старшокласників.

\title{
DEVELOPMENT OF THE SKILLS AND IMPROVEMENT OF THE MOTOR ABILITIES OF SENIOR STUDENTS IN PHYSICAL CULTURE LESSONS
}

\author{
Tovstopiatko F. F. \\ Ph. D. in Philology, Associate Professor, \\ Associate Professor at the Department of Theory and Methods \\ of Physical Culture and Sports \\ Zaporizhzhia National University \\ Zhukovskoho str., 66, Zaporizhzhia, Ukraine \\ orcid.org/0000-0002-4708-5916 \\ tovstopatkofedor@gmail.com \\ Tyshchenko V. O. \\ Doctor of Sciences in Physical Education and Sports, Professor, \\ Professor at the Department of Theory and Methods \\ of Physical Culture and Sports \\ Zaporizhzhia National University \\ Zhukovskoho str., 66, Zaporizhzhia, Ukraine \\ orcid.org/0000-0002-9540-9612 \\ valeritysh@gmail.com \\ Sokolova O. V. \\ Ph. D., Associate Professor, \\ Associate Professor at the Department of Theory and Methods \\ of Physical Culture and Sports, \\ Zaporizhzhia National University \\ Zhukovskoho str., 66, Zaporizhzhia, Ukraine \\ orcid.org/0000-0003-1062-0935 \\ sokolova-znu@gmail.com \\ Stiopochkin Y. S. \\ Master's Degree Student \\ at the Faculty of Physical Education, Health and Tourism \\ Zaporizhzhia National University \\ Zhukovskoho str., 66, Zaporizhzhia, Ukraine \\ orcid.org/0000-0001-6201-4596 \\ handball.survey@gmail.com
}


Key words: volleyball, variable module, physical fitness, technical fitness, youth.
An analysis of school physical education programs indicates that there is no real opportunity today to implement an important principle of the physical education system - to provide a differentiated and individual approach to students, taking into account their health, physical development and physical fitness. That is why the level of the development of motor skills of most high school graduates does not meet the requirements of society for the physical fitness of the younger generation. The purpose of the study is to increase the efficiency of skills development and improvement of motor skills of high school students in physical education lessons in the variable module "Volleyball". The objective of the research - is a physical education lesson in the variable module "Volleyball". The subject matter of the study is the indicators of physical and technical fitness. The subject of the study is high school boys. Research methods: analysis and generalization of literature sources on the research topic, pedagogical observations, testing of physical fitness, testing of technical fitness, methods of mathematical statistics. Results of the research. The analyzed scientific and methodical literature on the research topic allowed to study more detailed the features of physical and technical training in volleyball, the peculiarities of the development of physical qualities. The methodology was developed and tested in practice to increase the effectiveness of skills development and improve motor skills of high school students in physical education classes in a variable module "Volleyball". The use of the new, more effective pedagogical recommendations contributed to the formation of skills and improvement of motor skills of high school students in the process of volleyball in physical education classes. Conclusions. The use of experimental methods, in terms of monitoring the indicators of general physical fitness, as well as in the performance of technical elements of volleyball has increased the level of training of high school students.
Вступ. Останніми роками на тлі інтенсифікації навчального процесу в загальноосвітніх навчальних закладах спостерігається тенденція до зниження рівня здоров'я і фізичної підготовленості учнівської молоді [6]. Постійне збільшення обсягу навчального матеріалу, який має засвоїти сучасний школяр, майже не залишає йому часу на достатню рухову активність та фізичне самовдосконалення. Особливо гостро ця проблема постає перед учнями старших класів, які в умовах перевантаження шкільними предметами мають готуватися до ЗНО.

Актуальним питанням сьогодення $\epsilon$ розроблення й експериментальне обгрунтування ефективних засобів і методів розвитку рухових навичок у представників різних видів спорту, особливо в юнацькому віці, бо саме в цьому віці спостерігаються періоди найбільшого біологічного приросту фізичної якості [2-4]. Система фізичного виховання, яка склалася у школі (2 обов' язкові уроки на тиждень, низька моторна щільність та інтенсивність навантажень на них, недостатнє використання тренажерів, мала кількість занять просто неба тощо), не задовольняє потреб учнів у руховій активності. Варто зазначити, що позитивне ставлення учнів старшої школи до занять фізичною культурою має формуватися через усвідомлення вихованцями потреби у власному здоров'ї.
В учнів старшого шкільного віку простежується тенденція до зниження бажання займатися фізичними вправами, особливо на уроках фізичної культури. Важливим засобом фізичного виховання в цьому віці є спортивні ігри, яким належить важливе місце в системі освіти загальноосвітніх шкіл, на яких учням надається можливість виконувати ті спортивні вправи, які їм цікаві, від яких вони отримують задоволення.

Як свідчить практика, волейбол - один із найпоширеніших і доступних видів спорту, тому $€$ ефективним засобом залучення молоді та підлітків до систематичних занять фізичною культурою і спортом, який вимагає максимального прояву фізичних можливостей, вольових зусиль, уміння користуватися набутими навичками $[1 ; 5]$. Результатом удосконалення гри у волейбол $\epsilon$ сформованість навичок і умінь, застосування на практиці прийомів гри, прояв здібностей у разі участі у змаганнях різного рівня.

Мета дослідження - підвищити ефективність формування вмінь і вдосконалення рухових навичок старшокласників на уроках фізичної культури у варіативному модулі «Волейбол».

Поставлені завдання вирішувались із використанням таких методів дослідження, як:

1. Аналіз і узагальнення науково-методичної літератури.

2. Педагогічне спостереження. 
3. Педагогічний експеримент.

4. Тестування рівня фізичної підготовленості (біг на 6 м, с; човниковий біг 4 х 9 м, с; метання набивного м'яча, м; теппінг-тест, к-сть торкань; нахил тулуба вперед з положення сидячи, см; стрибок угору з розбігу, см; серійні стрибки вгору, к-сть торкань).

5. Тестування рівня технічної підготовленості (подачі м'яча у стрибку, бали; передача м'яча зверху двома руками над собою, к-сть разів; передача м'яча знизу двома руками, к-сть разів).

6. Визначення достовірності відмінностей середніх значень показників порівнюваних груп за t-критерієм Стьюдента 3 визначенням рівня можливої помилки досліджуваного порівняння (р) за таблицями. Достовірними вважали дані за рівня значущості $95 \%-\mathrm{p}<0,05$.

Організація дослідження. У нашому дослідженні брали участь 40 юнаків 16-18 років. Для перевірки ефективності розробленої нами методики було проведено педагогічний експеримент. Спортсмени були розподілені на 2 групи: контрольну (далі - КГ) і експериментальну (далі - ЕГ), по 20 осіб у кожній. Для виявлення вихідного рівня фізичної та технічної підготовленості перед початком педагогічного експерименту було проведено тестування за допомогою комплексу контрольних вправ.

У КГ тренувальні заняття проводилися за традиційною методикою, відповідно до програми 3 фізичної культури для загальноосвітніх навчальних закладів за варіативним модулем «Волейбол», затвердженої Міністерством освіти і науки України. В ЕГ використовувалася розроблена нами методика. Велика увага приділялася освоєнню специфіки просторово-часових і просторово-силових параметрів ігрових дій; розподілу і перерозподілу м'язових зусиль, співвідношенню тривалості дій у підготовчій, основній та заключній фазах. Так, під час силової подачі у стрибку задавався ритм розбігу; підкреслювався момент основної м'язової напруги в ударі по м’ячу і завершальних дій.

Виклад основного матеріалу дослідження. Для перевірки ефективності розробленої нами методики було проведено педагогічний експеримент. Також для об'єктивної інтерпретації результатів експерименту на початку дослідження показники всіх школярів не повинні мати статистично вірогідної різниці, що $\epsilon$ необхідною умовою. У доборі хлопців для проведення дослідження ми дотримувалися саме цих вимог.

Порівняльний аналіз результатів тестування на початку дослідження не виявив достовірних відмінностей за рівнем загальної фізичної підготовленості хлопців обох груп (p > 0,05). Аналогічна ситуація спостерігалася й за показниками технічної підготовленості на початку дослідження в учнів старшого шкільного віку контрольної й експериментальної груп.

Проведене дослідження рівня фізичної і технічної підготовленості хлопців старшого шкільного віку контрольної й експериментальної груп вказало на низку проблем освітнього процесу у варіативному модулі «Волейбол». Постала необхідність упровадження кардинальних змін у напрямі застосування методів i засобів навчання, що враховуватимуть сучасні вимоги школяра і сприятимуть ефективному навчанню. 3 урахуванням отриманих даних нами впроваджено розроблену методику проведення уроків фізичної культури у варіативному модулі «Волейбол» для вдосконалення цих показників старшокласників.

Для визначення впливу розробленої методики для підвищення ефективності формування вмінь і вдосконалення рухових навичок старшокласників на уроках фізичної культури у варіативному модулі «Волейбол» нами проведений аналіз динаміки показників фізичної та технічної підготовленості, які було зафіксовано на початку і в кінці дослідження.

Передусім варто відзначити, що у хлопців експериментальної групи протягом дослідження відбулись позитивні зміни за результатами практично всіх показників фізичної підготовленості. Так, у результаті проведення аналізу динаміки рівня розвитку фізичних якостей під впливом запровадженої методики варто відзначити, що у хлопців експериментальної групи відбулися статистично вірогідні зміни за всіма тестами. Динаміка показників фізичної підготовленості хлопців експериментальної групи протягом дослідження вказала на позитивний вплив і достовірні зміни між вихідними і прикінцевими значеннями. Так, статистично $(\mathrm{p}<0,05)$ підтверджено покращення рівня швидкісних здібностей у бігу на 6 м, результат зменшився на 0,3 с із $2,2 \pm 0,09$ на початку i до $1,9 \pm 0,09$ с після закінчення дослідження, що засвідчує зростання рівня їхнього розвитку на $13,64 \%$ у хлопців експериментальної групи. Результати тестувань аналогічної здібності у контрольної групи - збільшення на 8,26\%.

Підсумки статистичного аналізу даних щодо здібності до швидкісно-силових можливостей плечового поясу за метанням набивного м'яча у хлопців експериментальної групи свідчать про їх достовірне зростання після закінчення дослідження на 29,31\% від вихідного рівня $(\mathrm{p}<0,05)$, у хлопців контрольної групи - на 9,72\%. Також виявлені значні позитивні зміни $(\mathrm{p}<0,001)$ у значеннях показника, що характеризує загальні можливості прояву швидкості руху - теппінг-тесту хлопців експериментальної групи. Достовірність змін підтверджено на високому статистичному рівні $(33,4 \pm 0,8$ торкань і $37,6 \pm 0,5$ торкань) за зростання на 12,57 і $1,78 \%$ у хлопців контрольної групи. 
Статистично ймовірнісний аналіз результатів тестових випробувань, що характеризують здібність до гнучкості за нахилом тулуба вперед із положення сидячи, у хлопців ЕГ вказує на статистичну значущість $(\mathrm{p}<0,05)$ отриманих показників (11,3 \pm 0,7 см у первинній оцінці та 13,2 $\pm 0,2$ см наприкінці) та достовірну різницю між їхніми значеннями. Зафіксовано значні позитивні зміни в показниках швидкісно-силових здібностей хлопців ЕГ за стрибком вгору з розбігу, зокрема ïx достовірне $(\mathrm{p}<0,01)$ поліпшення на $11,42 \%$ від вихідного рівня $(64,8 \pm 1,7$ і $72,2 \pm 1,3 \mathrm{~cm})$ за $6,6 \%$ у хлопців КГ. Отримані в тестуванні за серійними стрибками вгору числові значення $10,9 \pm 0,5$ торкань на початку дослідження i $13,1 \pm 0,4$ торкань наприкінці засвідчили їхній достовірнийвпливпротягомдослідження $(\mathrm{p}<0,01)$.

У хлопців контрольної групи відбулося покращення результатів фізичної підготовленості без статистично достовірних змін між вихідними і кінцевими значеннями, крім бігу на 6 м. Подібні зміни відбулися й за показниками технічної підготовленості хлопців контрольної групи протягом дослідження. Лише за одним тестом «Передача м'яча згори двома руками над собою» відбулися достовірні зміни. Різниця між вихідними (3,8 $\pm 0,5$ разів) і прикінцевими $(5,4 \pm 0,5$ разів) значеннями становила 1,6 передачу - задовільний результат.
Порівняння прикінцевих значень вказало на достовірні зміни між обома групами за тестами:

- фізичної підготовленості: човниковий біг 4 х 9 м - p < 0,01; метання набивного м'яча $\mathrm{p}<0,05$; теппінг-тест $-\mathrm{p}<0,001$; стрибок угору 3 розбігу - $<<0,01$; серійні стрибки вгору $\mathrm{p}<0,01$

- технічної підготовленості: подачі м'яча у стрибку - $<<0,001$; передача м'яча зверху двома руками над собою $-\mathrm{p}<0,01$; передача м'яча знизу двома руками $-\mathrm{p}<0,05$.

Показник t-критерію Стьюдента, за всіма проведеними контрольними випробуваннями, виявився в зоні значущості, що підтверджує позитивний вплив нашої методики на уроках фізичної культури у варіативному модулі «Волейбол» на рівень технічної підготовленості старшокласників.

Висновки. Результати показників фізичної та технічної підготовленості старшокласників на уроках фізичної культури у варіативному модулі «Волейбол» протягом дослідження в експериментальній групі під впливом упровадження розробленої методики достовірно виросли щодо контрольної групи, у якої тренувальні заняття проводилися за традиційною методикою. Доведена ефективність формування вмінь і вдосконалення рухових навичок старшокласників на уроках фізичної культури у варіативному модулі «Волейбол».

\section{ЛIТЕРАТУРА}

1. Горбачева Е.Н., Сираковская Я.В., Шкирева О.В. Формирование двигательных навыков старшеклассниц в процессе занятий волейболом на уроках физической культуры. Проблемы совершенствования физической культуры, спорта и олимпизма. 2018. № 1. С. 39-44.

2. Гринченко І.Б., Коваленко С.В., Воронов Ю.В. Вплив авторської програми навчально-тренувального збору з фізичної підготовки на фізичну і функціональну підготовленість кваліфікованих волейболістів. Спортивні ігри. 2019. № 4 (14). С. 13-23.

3. Демчишин А.А., Пилипчук Б.С. Подготовка волейболистов. Киев : Здоровье, 1989. 104 с.

4. Контроль навчально-тренувального процесу у волейболі / О.В. Жула та ін. Наукові дискусіӥ кафедри педагогіки, психології і методики. 2018. 20 с.

5. Кічук С.Ф. Методичні аспекти навчання техніки гри у волейбол. Тернопіль : ТНПУ, 2017.59 с.

6. Ковцун В.I. Волейбол : основи техніки і тактики гри у волейбол : методичний матеріал для лекцій 3 теорії та методики викладання волейболу. Львів : Фернеза, 2016. 33 с.

\section{REFERENCES}

1. Gorbacheva Ye.N., Sirakovskaya Ya.V., Shkireva O.V. (2018). Formirovaniye dvigatel'nykh navykov starsheklassnits $\mathrm{v}$ protsesse zanyatiy voleybolom na urokakh fizicheskoy kul'tury [Formation of motor skills of high school girls in the process of volleyball lessons at physical culture lessons]. Problemy sovershenstvovaniya fizicheskoy kul'tury, sporta i olimpizma. № 1. S. 39-44.

2. Hrynchenko I.B., Kovalenko S.V., Voronov Yu.V. Vplyv avtors'koyi prohramy navchal'no-trenuval'noho zboru z fizychnoyi pidhotovky na fizychnu i funktsional'nu pidhotovlenist' kvalifikovanykh voleybolistiv [Influence of the author's program of educational and training collection on physical training on physical and functional readiness of qualified volleyball players]. Sportyvni ihry. 2019. № 4 (14). S. 13-23.

3. Demchishin A.A., Pilipchuk B.S. Podgotovka voleybolistov [Volleyball players training]. Kiyev : Zdorov'ye, 1989. 104 s.

4. Zhula O., Serheyeva A., Lytvynova A., \& Zhula L. Kontrol' navchal'no-trenuval'noho protsesu u voleyboli [Control of educational and training process in volleyball]. Naukovi dyskusiyi kafedry pedahohiky, psykholohiyi i metodyky, 2018. 20 s.

5. Kichuk S.F. Metodychni aspekty navchannya tekhniky hry u voleybol [Methodical aspects of teaching volleyball technique]. Ternopil' : TNPU, 2017. $59 \mathrm{~s}$.

6. Kovtsun V.I. Voleybol : osnovy tekhniky i taktyky hry v voleybol [Volleyball: basics of technique and tactics of volleyball]: metod. material dlya lektsiy z teoriyi ta metodyky vykladannya voleybolu. L'viv : Ferneza, 2016. 33 s. 